\title{
Bench Tests: Activities Report
}

\author{
Arthur Vianna Dias da Silva Brim ${ }^{1 *}$, Gustavo Moura Costa ${ }^{2}$ \\ ${ }^{1}$ EMBRAPII; ' 2 SENAI CIMATEC Universitary Center; Salvador, Bahia, Brazil
}

Laboring with electronics involves difficulties and sources of error, which sometimes causes the malfunction of the equipment. It is necessary to carry out inspection activities to locate points of uncertainty, isolate them and test the system without their interference to recognize a source of non-conformities and solve it. The article presents the activities of electronic systems enclosed in a prototype, describing the faults detected and the improvements implemented.

Keywords: Electronics. Tests. Inspection.

\section{Introduction}

Sensory deprivation tanks applied in restricted stimulus control therapies were conceived in 1954 by John C. Lilly, a physician, and neuroscientist engaged in the origin of consciousness [1]. The EMBRAPII Floatation Tank project designed the construction and testing of a modern flotation tank, applying modern communication and control systems for the elements inside and outside the capsule.

There are many steps to approve equipment. The bench tests are the ones of these steps. It consists of a simple activating of the components to assure that what the supplier points out corresponds to reality. Energizing the equipment and performing a visual inspection of its operation is usually sufficient for this type of activity, in the case of commercial items. Occasionally it may be necessary to use a bench source [2] or multimeter [3] to measure the electric current or voltage applied to the equipment.

For systems developed within the scope of research, the procedure acquires a more detailed aspect since it should be guaranteed all operating requirements contemplated. These requirements

\footnotetext{
Received on 7 March 2021; revised 10 May 2021.

Address for correspondence: Arthur Vianna Dias da Silva Brim. Av. Orlando Gomes, 1845 - Piatã, Salvador - BABrazil. Zipcode: 41650-010. Phone: (71) 3462-8449 / 99911 1212. E-mail: arthur.brim@fbter.org.br. Article selected from VI SENAI CIMATEC Scientific and Technological Research Evaluation Seminar - 2021.
}

J Bioeng. Tech. Appl. Health 2021;4(2):49-51.

(C) 2021 by SENAI CIMATEC. All rights reserved. are usually but not limited to power dissipation, operating voltage, response time, maximum current $[4,5]$.

This study aims to approach the inspection and validation of the chromotherapy circuits and prototype load activation of the Floatation Tank project.

\section{Material and Methods}

The analysis procedure begins by consulting the circuit diagram in question. It is possible to determine the scope of the circuit and the operation condition through the guidelines and the designer's comments. Once these points are delimited, a test bench is setting up using a voltage source to supply power to DC circuits or a safety relay to AC circuits.

Then, the circuit is activated to inspect it, following the guidelines. In case of failure, the first step is to ensure that the command signal reaches the destination terminal. Afterward, you can examine other sources: component power, solder quality, the material quality of the component. Another applicable measure is to review the datasheet or the report technique applied to the element to ensure that the model designed in the project matches reality.

If none of the above measures show results, the component must be replaced by a new one.

\section{Results and Discussion}

The RGB LEDs for chromotherapy are inspected first. Next, there is the schematic for 
activation [Figure 1]. Through it, a command must activate the MOSFET [6] to connect the GND signal to the LED, activating a green color. The same circuit is repeated for the red and blue colors. A MOSFET6 is an electronic switch controlled by voltage, controlled by a command. It allows the passage of current (without the command there is no passage) $[4,5]$.

Figure 1. MOSFET key.

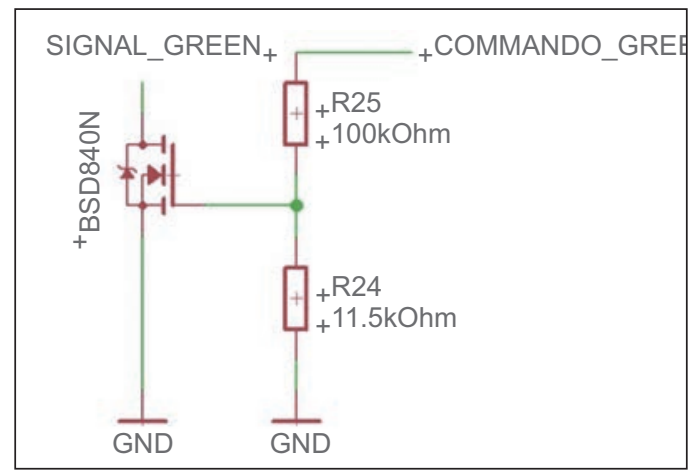

The bench tests proved the luminous intensity of the equipment, as well as the possibility of controlling which of the basic colors is activated (Red, Green, and Blue) and its intensity. A 1-hour floating session was simulated and the lamps did not show negative results.

The following circuit is for low-current AC load drives (Figure 2). During bench tests, improvement points were identified. The specified relay [7] presented tolerance for voltages up
Figure 2. VI load activation.

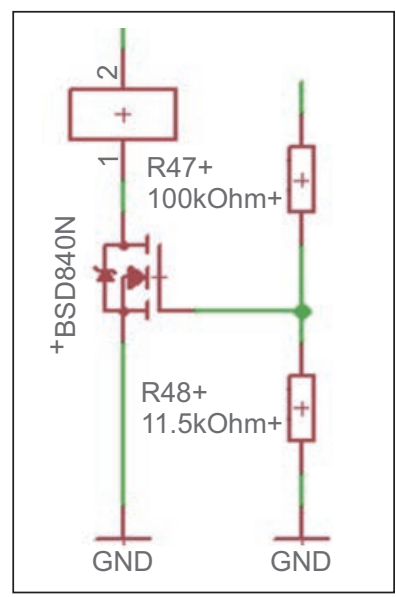

to $110 \mathrm{~V}$ in the first instance, which makes the system incompatible for bivolt installations. We observed that MOSFET [6] is crucial for the correct operation of the circuit. The system was tested with the coil activation command coming directly from the control unit [8]. However, this unit does not have the current capacity to guarantee the relay energization. Thus, MOSFET [6] acts by connecting the coil directly with the reference from a low current command coming from the controller [8].

The circuit for activating high currents uses a TRIAC as an electronic switch - component indicated in the literature for high current loads and heat dissipation [4,5]. During bench tests, we observed an error in the schematic representation of the MOC3032SM component. The connections

Figura 3. High current activation.

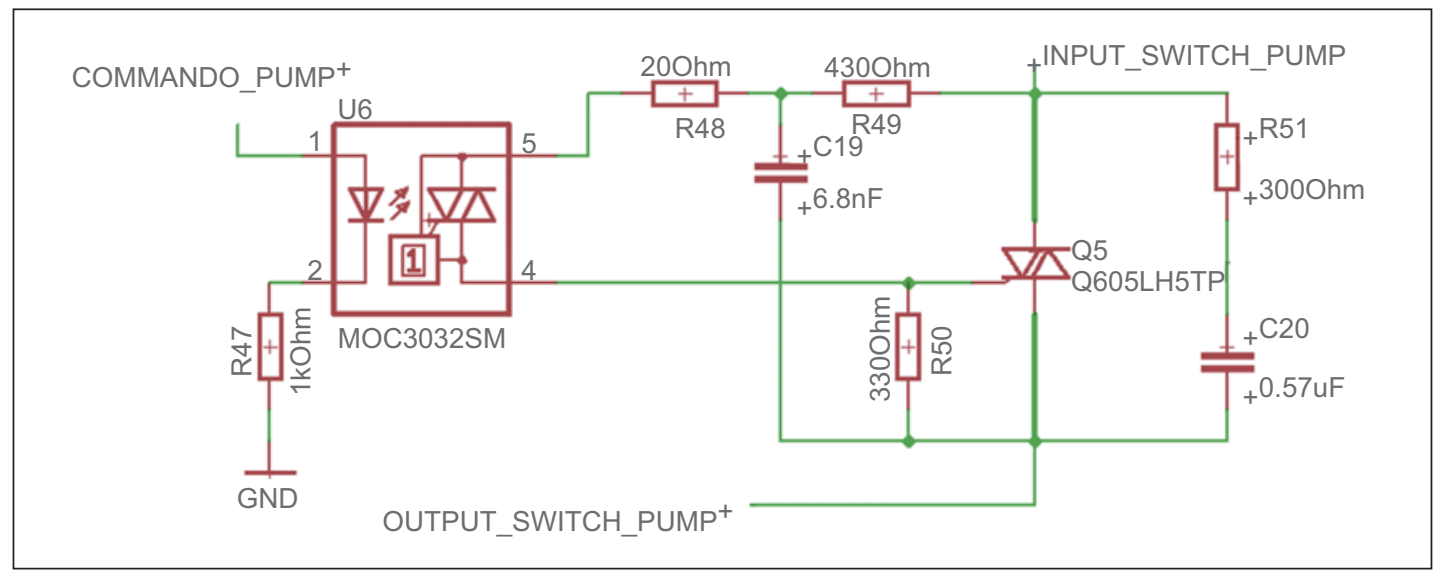


presented in the schematic were not consistent with those indicated in the technical report. Moreover, during circuit stress tests, the Q605LH5TPcomponent got hot beyond the recommended limit despite the heat dissipation scaling. So, we proposed increasing the heatsink coupled to the electronic key to preventing damage to the component. However, we perceived a space limitation during the assembly procedure of the printed circuit board. Thus, the bench test pointed out that another electronic element is necessary to perform this function.

\section{Final Considerations}

We verified the precise operation of a proposed circuit and identified improvements in another one through bench tests. Therefore, the importance of the bench tests procedure to identify and correct failures without huge impacts on the project becomes evident.

\section{Acknowledgements}

Our thanks to CNPq, EMBRAPII e SENAICIMATEC o the financial and technical support.

\section{References}

1. Helathline. Sensory Deprivation Tank. Disponível em: https://www.healthline.com/health/sensorydeprivation-tank\#1. Acesso em: 7 abr. 2021.

2. Minipa. MLP-1305M. Disponível em: https://www. minipa.com.br/instrumentos-de-bancada/fontes-dealimentacao/133-mpl-1305m. Acesso em: 8 abr. 2021.

3. MINIPA. ET-1110A. Disponível em: https://www. minipa.com.br/categoria/1/multimetros/2-et-1110a. Acesso em: 8 abr. 2021.

4. Alexander C, Sadiku MN. Fundamentos de Circuitos Elétricos. Porto Alégre: Bookman, 2013.

5. Boyestad R. Dispositivos Eletrônicos e Teoria dos Circuitos. São Paulo: Pearson, 2013.

6. Mouser. BSD840N. Disponível em: https://br.mouser. com/ProductDetail/Infineon-Technologies/BSD840N$\mathrm{H} 6327 /$ ?q $=$ oPPfIaWL110H7MAyCvvoCQ\%3D\%3D. Acesso em: 8 abr. 2021.

7. Mouser. G6L-1F-DC5. Disponível em: https:// br.mouser.com/ProductDetail/Omron-Electronics/ G6L-1F- DC5?qs=VO24nqdQNUCxpZtfAaMOMg\% 3D\%3D. Acesso em: 8 abr. 2021.

8. Altus. CLP nexto express com suporte a webserver. Disponível em: https://www.altus.com.br/post/294/ conheca-o-xp340-2c-clp-nexto-xpress-com-suporte-awebserver. Acesso em: 8 abr. 2021.

9. Mouser. G5V-1-DC3. Disponível em: https://br.mouser. com/ProductDetail/Omron-Electronics/G5V-1- DC3?q $\mathrm{s}=\%$ 2Fvla5QEfK\%2FLM9AQD4QUVGA\%3D\%3D. Acesso em: 8 abr. 2021. 